\title{
Revolta de escravizados na ilha de Santiago: fragilidade e inconsistência governativa em Cabo Verde (1835)
}

\section{Uprising of slaves on the island of Santiago: fragility and inconsistency in government in Cape Verde (1835)}

\section{Alan de Carvalho Souza}

Como citar esse artigo. SOUZA, A.C. Revolta de escravizados na ilha de Santiago: fragilidade e inconsistência governativa em Cabo Verde (1835). Revista Mosaico, v.12, n.1, p. 38-47, 2021.

\section{Resumo}

O artigo apresenta a inédita revolta escrava ocorrida na ilha de Santiago, Cabo Verde, que objetivou o apoderamento dos quartéis, do paiol de pólvora e a morte dos proprietários; revelando a fragilidade da guarnição existente e a consequente incapacidade de resposta. Ocorrida após o período de seca que se abateu sobre o arquipélago no início da década de 1830 e, posteriormente, à proibição do comércio de escravizados pelo Brasil, a insurreição de dezembro de 1835 é mais uma ocorrência da agitada e instável década e parte do processo de deslocamento de um império antes centrado na ex-colônia americana. $\mathrm{O}$ levante exemplifica, uma vez mais, igualmente ao observado no Brasil a inconsistência da governação na conflagração de sublevações, neste caso, no império português.

Nota da Editora. Os artigos publicados na Revista Mosaico são de responsabilidade de seus autores. As informações neles contidas, bem como as opiniões emitidas, não representam pontos de vista da Universidade de Vassouras ou de suas Revistas.

Palavras-chave: revolta escrava; Cabo Verde e instabilidade política.

\begin{abstract}
This article presents the unprecedented slave revolt on the island of Santiago, Cape Verde, which aimed at the seizure of barracks, the powder magazine and the death of the owners; revealing the fragility of the existing garrison and the consequent inability to respond. Occurring after the drought that hit the archipelago in the early 1830 s and, subsequently, to the prohibition of the slave trade by Brazil, the December 1835 insurrection is yet another occurrence in the agitated and unstable decade and part of the process of displacing an empire that once centered on the former American colony. The uprising exemplifies, yet again, what was observed in Brazil the inconsistency of governance in the conflagration of upheavals, in this case in the Portuguese empire.
\end{abstract}

Keywords: slave insurrection; Cape Verde and political instability.

Cabo Verde teve suas primeiras ilhas (Santiago, Fogo, Maio, Boa Vista e Sal) "descobertas" em 1460. Entretanto, a ocupação do território iniciou-se por Santiagoem 1462 comgenoveses, portugueseseafricanos (CARREIRA, 1983, p. 23) ${ }^{1}$. O interesse inicial era o econômico e por essa razão, segundo Danilo dos Santos, numa primeira fase foram atraídos os comerciantes (SANTOS, 2012, p. 54), mas não só. Degredados foram integrados à formação daquela sociedade chegando a ocupar cargos de grande relevância. Contudo, desde a ocupação inicial percebeu-se a necessidade da utilização de escravizados africanos (CARREIRA, 1983, p. 29), o que mais tarde daria origem ao processo de mestiçagem no arquipélago.

A utilização de escravizados, sobretudo oriundos da costa da Guiné, buscou suprir a escassez de mão de obra e mais tarde passou para o tráfico negreiro.

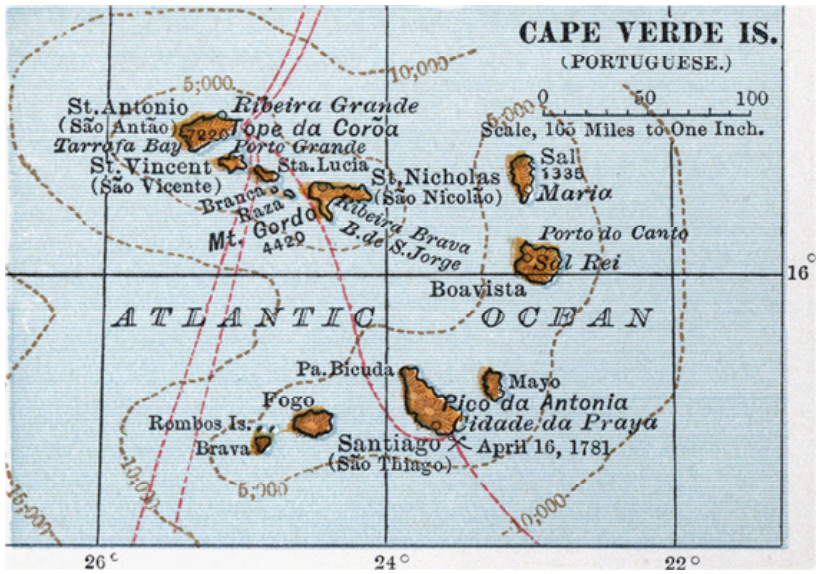

Figura 1. Mapa de Cabo Verde².

Afiliação do autor:

Instituto de Ciências Sociais (ICS) da Universidade de Lisboa, Lisboa, Portugal.

*Email de correspondência: ppunk_alan@hotmail.com 
Com uma população composta majoritariamente de escravizados, a ocorrência de fugas era comum. Em razão da existência de ataques realizados por estrangeiros em busca de escravos, os próprios proprietários incentivavam evasões como forma de proteger os seus cativos, consequentemente, o investimento. Esses assaltos, contudo, ocasionavam o desaparecimento dos escravizados e o despovoamento do território, caso observado na ilha de Santiago após uma investida francesa em 1712 (PUSICH apud CARREIRA, 1983, p. 328). Porém as ocorrências de fugas, sejam elas resultados dos assaltos "piratas", sejam elas, sobretudo, forma de resistência ao trabalho forçado, ocasionaram o abatimento da agricultura. Em 1804, o governador António Coutinho de Lencastre ordenou a criação da função de capitão do mato e meirinho da serra em cada freguesia do arquipélago para tratarem dos escravos fugidos e das pessoas que ocultavam as fugas (CARREIRA, 1983, p. 348).

A história de Cabo Verde apresenta narrativas diversas. Assim, escolhemos entre tantas, uma que se aproxima mais do objeto de análise deste artigo. Desse modo, apresentamos o relato de Ilídio Baleno, para o qual Cabo Verde serviu de laboratório onde o modelo escravocrata foi testado pela primeira vez. Segundo Baleno, tal modelo foi implantado com sucesso na ilha de Santiago e na ilha do Fogo durante o século XV (BALENO, 2006, p. 150). Entretanto, no Oitocentos, a norma já não atendia as necessidades do arquipélago, principalmente após a fuga da corte portuguesa, da assinatura do tratado de 1815 e da proibição da comercialização de escravizados a partir de 1830 pelo Brasil.

A ilha de Santiago, reconhecida pelo seu papel no tráfico, apresentava no decênio de 1830 baixo contingente de escravizados. Todavia, o ordinário percentual não impossibilitou o surgimento de revolta. Mais do que a conflagração da insurreição, há de salientar o período em que a mesma ocorreu. Porém, antes de apresentarmos o contexto, há de destacar a importância do arquipélago para o comércio de escravizados. Relevância acentuada durante o período pombalino com o direcionamento daquele comércio ao Brasil por meio da aplicação de medidas como: concessão da liberdade aos portugueses de comercializarem africanos de Moçambique com o Brasil (CAPELA, 1974, p. 154) e a aplicação de ações de incentivo ao tráfico destinado ao Brasil ao diminuir o juro do crédito a longo prazo de $5 \%$ para $3 \%$ para, posteriormente, abolir a cobrança (CAPELA, 1974, p. 150), e a publicação do Alvará Régio de 1761 que proibiu o desembarque de escravizados em solo metropolitano com a pena de ser transformado em forro ${ }^{3}$.

O envolvimento cabo-verdiano no comércio de escravizados ocorria por meio das barganhas realizadas pelas embarcações que se abasteciam com produtos de primeira necessidade em suas escalas até o embarque, principalmente, em Angola ou desembarque no Brasil.

Em razão desse tipo de envolvimento, o impacto da proibição da comercialização de escravizados ao norte da linha do Equador quase não alterou o dia a dia do arquipélago. Em comunicação do governador de Cabo Verde sobre a proibição (1815), o baixo impacto da repressão é percebido. O ofício de seis laudas dedicou apenas um único parágrafo (PEREIRA, 2016, p. 267) sobre a questão e limitou-se a informar sobre o recebimento do aviso da proibição e das ordens expedidas aos "Commandantes Respectivos das Ilhas, a Praça de Guiné [...] o disposto na Convenção e Tratado [...] de ter cessado o trafico da Escravatura ao Norte do Equador."4

Além de servir de escala para o reabastecimento das embarcações envolvidas no comércio de escravizados, a circulação de ideia e boatos ${ }^{5}$ oferecia uma maior identidade com o Brasil do que com Portugal, o que terminava por proporcionar a mudança de alguns colonos para a colônia portuguesa na América. Mais tarde, a notícia sobre a independência brasileira gerou à vontade e/ou do desejo de emancipar-se da coroa portuguesa. Desejo manifestado pelo negociante e deputado às Cortes, Manoel António Martins, acusado pelo governador António Pusich ${ }^{6}$ de executar um projeto de emancipação e de querer vender as ilhas de São Vicente e do Sal aos ingleses. (PEREIRA, 2013).

Manoel António Martins não foi o único a buscar a separação. Em 1821, foi constituída uma Junta de Governo que excluiu o governador António Pusich. A Junta assumiu a responsabilidade do projeto separatista com o apoio dos ingleses (PEREIRA, 2013, p. 132). Entretanto, o projeto não teve o apoio incondicional da população, ao menos da ilha de Santiago, não demonstrando a recepção que se esperava na proposta de se unir ao Brasil (PEREIRA, 2013, p. 132).

Ao observar os acontecimentos do arquipélago, percebe-se que a ilha de Santiago era, de certa forma, um centro "catalisador". Foi modelo escravocrata, desempenhou importante papel no tráfico e foi o local onde se constatou o desejo, por parte da elite dirigente, de anexação ao Brasil.

Quando da emancipação do Brasil com a permanência de tarifas diferenciadas sobre seus produtos, houve insatisfação em Cabo Verde. O motivo apresentado era que o benefício prejudicava o desenvolvimento agrícola, consequentemente econômico. Fato que se verifica na morte do rei D. João $\mathrm{VI}^{7}$, quando a preocupação do governo da possessão pausou sobre o não recebimento de "socorros alguns pecuniários", que levaram "a consternação [...] geral". A razão do receio residia na sobrecarga de "huma enorme dívida" e no atraso de quatro meses do pagamento da "officialidade e Empregados públicos."

Ainda durante a época de negociação para o reconhecimento da independência do Brasil, publicou- 
se o alvará régio de 6 de dezembro de 1824 que buscava o recíproco "Commercio de Seus Reinos com o de Angola". Contudo, tal publicação não procurou alterar a relação existente do reino com Cabo Verde. ${ }^{9}$

Mesmo tratando-se de um rico e importante período da História da relação de Portugal com os seus domínios, a historiografia referente às possessões africanas durante o período em que ocorreu a fuga da corte para o Rio de Janeiro e a independência brasileira é parca. Gabriel Paquette, quando analisou as ideias e projetos portugueses para o império no período de 182050 , foi categórico ao afirmar a existência de um hiato na historiografia sobre o período imediato de "perda" do Brasil e de crescente atenção à África. A escassez de estudos sobre os projetos e propostas dedicados as possessões africanas é interpretada por Paquette como resultante da agitação política e da guerra civil vivenciada por Portugal na primeira metade do XIX que, segundo o pesquisador, levaram "historiadores interessados em resultados, em políticas concretas, ignorar, justificadamente, os muitos projetos não realizados que proliferaram (PAQUETTE, 2010). ${ }^{10}$

Exemplificando o aumento do interesse português sobre os domínios em África o projeto do deputado José Antonio Ferreira Braklami (CASTRO, 2002, p. 262264), ${ }^{11}$ apresentado em 11 de dezembro de 1826, que propunha "promover, e adiantar quando suas forças, e faculdades permittem, a População, Agricultura, Commercio, e Industria, e Navegaçao" das possessões em África. ${ }^{12} \mathrm{O}$ projeto assentava em isentar e cortar pela metade as taxas e direitos de importação na metrópole. De acordo com a proposta, o objetivo dos cortes era incentivar a produção e o povoamento e a colonização das possessões, que em função do predomínio do Brasil ficaram em segundo plano e, na maioria das vezes, desempenharam a função de fornecedora de mão de obra escrava que produzia e explorava a riqueza da excolônia (ALEXANDRE, 2008, p. 106).

Mas a proposta não avançou. $O$ benefício alfandegário aos gêneros "brazílicos" dava-se em razão da escassez produtiva portuguesa e da movimentação comercial gerada na rota Brasil/Angola/Brasil com a importação sempre a crescer de escravizados. Tal privilégio dificultava ainda mais o desenvolvimento de Cabo Verde que lutava e buscava desenvolver e expandir a agricultura, e encontrava na taxação sobre a exportação de sua produção uma das principais barreiras.

Os comerciantes consideravam a taxação incoerente e a apontava como a "principal" razão pela improdutividade das ilhas que exemplificavam o "absurdo" "que huma arroba de Caffe de Cabo Verde para muito perto de $1 \$ 800$ reis e a mesma arroba de Caffe brazileiro sobe mui pouco de 600 reis, sem que o consumidor de maior valor aquelle do que a este. Que taes são os males que afligem e conservão improdutivas as Ilhas de Cabo Verde". ${ }^{13}$
Em 19 de junho de 1826, a Real Junta do Comércio recebeu a Representação dos Comerciantes da praça de Lisboa, a qual solicitava providências acerca do estado em que se encontravam as ilhas de Cabo Verde e a isenção do pagamento dos direitos por determinado período até alcançar uma constante e maior produção, pagamento de $10 \%$ ad valorem para a exportação ou mantimento de navios e a redução dos $30 \%$ de direito de importação e consumo mais a equiparação e favorecimento do ingresso da produção de Cabo Verde nos mercados de Portugal. $^{14}$

A relação da metrópole com o seu domínio não apresentava problemas apenas nas taxações sobre os gêneros que produzia. Existiam ausência de comunicação e estabelecimento de uma rota comercial. Portugal sequer era o principal parceiro comercial de Cabo Verde.

Em 1826, a receita alfandegária da ilha de São Nicolau foi de apenas $438 \$ 353^{15}$ com as embarcações norte-americanas dominando a relação comercial. Naquele ano ${ }^{16}$, a presença norte-americana também se verificou na ilha de Santo Antão. Essas informações confirmam a referência de Orlando Ribeiro de serem os Estados Unidos os principais parceiros comerciais do arquipélago. ${ }^{17}$

Se os norte-americanos exerciam tal função, o Brasil, por sua vez, era o responsável pela contribuição essencial à agricultura; conforme salientou o mesmo Orlando Ribeiro que "embora o maior número de plantas cultivadas fosse trazido de Portugal, as mais importantes são oriundas da América Tropical e algumas do Oriente" (RIBEIRO, 1997 p. 106).

Assim, tínhamos até o reconhecimento da independência do Brasil por Portugal, uma maior ligação da província com a ex-colônia, que contribuia para o desenvolvimento da agricultura enviando plantas (SOUZA, 2020) que se apresentaram de grande importância para Cabo Verde.

\section{O fator instabilidade}

Em Cabo Verde, os militares eram um dos problemas enfrentados e a gerar instabilidade. Se em meados do mês de dezembro de 1825 o presídio de Cacheu" "foi atacado com grandes forças pelos Gentios;" "20 tratando-se de "huma trama fatal, urdida pelo ex-juiz do Povo, Pedro Gomes, induzio os Gentios a huma tal guerra (...)." ${ }^{\prime 21}$ No ano seguinte, a própria Guarnição se sublevava. Foi o que ocorreu no ano de 1826 na Praça de "São Joze de Bissau 22 ." Ao que tudo indica um dos motivos foi a ausência de pagamento dos vencimentos das Tropas. Em comunicação de 17 de julho de 1826 informou que as

urgentíssimas providencias [... a fim de manter a tranquilidade publica, e conservar indeléveis a fidelidade e 
obdiencia destes Povos (...) que as sobreditas providencias tiverão o mais prompto e saudável effeito por que pagos em dia os atrazados vencimentos da Tropa e Empregados de todas as classes, e satisfeitos muitos particulares que erão credores (...) foi por tanto sofocada a principal origem do publico [o] descontentamento que anteriormente se observava (...). ${ }^{23}$

Juntam-se a esse quadro, anos finais do decênio de 1820 , a instabilidade política em Portugal e o conturbado cenário político do Brasil que apresentava perspectiva não muito diferente. Insurgências regionais, como a Confederação do Equador, ${ }^{24}$ contribuíram para a instabilidade política e financeira que se agravou após a derrota na campanha da Cisplatina. ${ }^{25}$ Durante esse período, segunda metade da década de 1820, o Brasil acorda com a Inglaterra a ilegalidade do comércio de escravizados a vigorar a partir de março de 1830. Logo após o tratado, ${ }^{26}$ já independente, o país vivenciou a abdicação do imperador d. Pedro I. ${ }^{27}$ Muito desgastado politicamente com a derrota acima citada, piora da economia, aumento do custo de vida, desvalorização da moeda e a perda do apoio do exército brasileiro. ${ }^{28}$ A saída foi "entregar" a governação do império a uma junta governativa até a maioridade do filho d. Pedro. Já sob a regência e poucos meses após a abdicação, no dia 7 de novembro de 1831, publicou-se a lei antitráfico.

Naquele mesmo ano surgiu a primeira tentativa de revolta de escravizados em Carrancas que se concretizou em 1833 (ANDRADE, 1999). Em janeiro de 1835, ocorreu a revolta dos Malês (REIS, 2012) que ofereceu mais instabilidade ao cenário regencial. Foi durante o período de inconstância política tanto no Brasil quanto em Portugal o momento de eclosão de várias revoltas. ${ }^{30}$

No Brasil, as revoltas e insurreições aconteciam em momentos de divisão senhorial (SILVA e REIS, 1989, p. 10; ENGEMANN, 2008, p. 149), ou seja, quando a elite se encontrava em disputa, por exemplo, pelo poder local (SOUZA, 2012). Mas, sobretudo, as revoltas ocorriam em momentos de instabilidade política. A década de 1830 foi uma época de instabilidade no império do Brasil e no reino de Portugal, período em que o tráfico foi posto na ilegalidade para retirar dos ingleses a jurisdição sobre o aprisionamento das embarcações destinadas ao Brasil, que ocasionou consequências financeiras negativas nas possessões portuguesas em África (SOUZA, 2020). ${ }^{31}$

Mediante ao agravamento econômico que causaria a proibição brasileira, d. Miguel, após tomar o trono português, publicou um novo alvará régio que na prática representava o rompimento com a administração destinada as colônias portuguesas ao reduzir os direitos pagos pelos gêneros coloniais nas alfândegas do reino para $10 \% .{ }^{32}$

Se a ilegalidade do comércio de escravizados já havia sido acordada por d. Pedro I; após a promulgação da lei de 1831 passou a discutir no Brasil a formação da regência e a votação dos respectivos regentes. Por sua vez, Portugal ainda vivenciava a disputa pelo trono que ocasionou o fechamento da Câmara dos Deputados e, posteriormente, a queda de d. Miguel; por fim, a reabertura em 1834 da Câmara dos Deputados e um novo reinado.

Quando da ocorrência da "revolução" escrava de Cabo Verde em dezembro 1835, a possessão tentava suprir as necessidades mais básicas da população após grave seca que provocou a morte de milhares de habitantes. O desastre vivido pelo arquipélago ocasionou o recebimento de ajuda norte-americana em 1833, após o pedido de socorro realizado pelo governador-geral ao capitão Ridder. ${ }^{33}$ A comunicação à Secretaria de Estado dos Negócios Estrangeiros sobre o que sucedia na possessão ocorreu somente depois do "Encarregado de Negocios de Sua Majestade nos Estados Unidos da America" receber as informações do citado capitão. A primeira ajuda ocorreu por meio do navio "Baleeiro de Ness Bedford [que] largou alguns dos seus mantimentos na ilha Brava e nas ilhas de Maio e da Boa Vista a troco de Sal". ${ }^{34}$

Na sequência do pedido do governador geral de Cabo Verde, os habitantes de Boston "convocarão hum Ajuntamento na Caza de Camara Municipal para dali deliberarem sobre os meyos de reduzirem a mizeria dos pobres habitantes das ilhas de Cabo Verde". ${ }^{35}$ Tal reunião apresentou resultado com a "Casa de Comércio de $\mathrm{P} \& \mathrm{C}$ Tlink\& $\mathrm{C}$ de Boston offerecerão se para exportarem livre de frete [...] huma porção de gêneros que possa caber nhum vão que deitará de 5 para seis centos barris de Farinha, sendo para socorrer os Ilheos infelizes". ${ }^{36}$

Tabela 1. Produtos enviados pela Comissão da Caridade - New York $1833^{37}$.

\begin{tabular}{|l|l|}
\hline Produtos & Quantidade \\
\hline Sacas de milho & 720 \\
\hline Barris de farinha de milho & 300 \\
\hline Barris de farinha de trigo & 21 \\
\hline Barris de farinha de levada & 6 \\
\hline Barris de bolacha & 600 \\
\hline Barris de batata & 22 \\
\hline Barris de carne de vaca & 14 \\
\hline Barris de corações de vaca & 2 \\
\hline Barris de porco & 2 \\
\hline Barris de feijão & 36 \\
\hline Barris de arroz & 333 \\
\hline Barris de "bolaxa" fina & 2,5 \\
\hline Barris de ervilha & 1 \\
\hline Barris de cebola & 1 \\
\hline Pipas de bolacha & 2 \\
\hline Sacas de bolacha & 100 \\
\hline $\begin{array}{l}\text { Caixões de anzóis, linhas para } \\
\text { pescaria }\end{array}$ & 1 \\
\hline Rolos de chumbo para pescaria & 2 \\
\hline Total de volumes & $\mathbf{2 . 1 6 5 , 5}$ \\
\hline
\end{tabular}

Fonte: Elaborada pelo autor 
A ajuda norte-americana foi crucial para Cabo Verde sobreviver ao flagelo em que se encontrava; a Junta da Fazenda do arquipélago afirmou que "[...] os habitantes que tem escapado aos estragos de uma fome tão devastadora [...]" a proeza deve-se ao socorro "[...] em mantimentos pela philantropia dos cidadãos dos Estados Unidos da America". ${ }^{37}$ Três anos após (1836) o recebimento do socorro norte-americano, a ilha de São Nicolau produziu apenas "quinhentos moios, e faltãolhe outros quinhentos para o seu consumo [...]". ${ }^{38}$

Enquanto os Estados Unidos enviaram a ajuda acima citada, a oferecida pelo "EllRey" foi de "[...] que mandasse por a disposição [...] cento e cincoenta moios de milho [...]." "40 Portugal vivenciava desde os anos finais do decênio de 1820 uma grave crise econômica, afora a escassez de gêneros. Ainda em 1828 , os deputados portugueses já consideravam para a "[...] Nação Portuguesa a mais horrível catastrophe financeira. [...] O Governo apresenta-nos este anno um deficit de dez milhões [...]." ${ }^{\text {41 }}$

Mais informações sobre a situação econômica de Portugal foram encontradas após a reabertura da Câmara dos deputados em 1834. Em documento apresentado aos deputados sobre a importação e exportação com o "Brasil, Inglaterra e mais Nações Estrangeiras", no ano de 1828 as importações alcançaram 12.019.196\$804 e as exportações 10.782.763\$547, com déficit de 1.236.433\$258 cruzados. $^{42}$ Problema financeiro que se agravou nos dois anos seguintes, com déficits de $2.183 .169 \$ 941$ e $2.449 .273 \$ 624$ cruzados ; e que se

majoraria com a ilegalidade do comércio de escravizados a partir de 1831 .

O contexto econômico/político do Atlântico Sul era de instabilidade. Se para Portugal a década de 1830 foi de extrema carência econômica, por sua vez, após toda a disputa pelo trono e fechamento e reabertura da Câmara dos deputados, a política não oferecia o equilíbrio necessário num momento de agravamento da perda de receita e de revoltas nos domínios em África.

Em Moçambique, o Corpo da Guarnição da Praça de São Sebastião rebelou-se em 26 de maio de 1836 e no dia 14 de junho do mesmo ano, descobriu-se "o horrorozo plano da mesma Soldadesca de assassinar os Oficiais [...] e darem hum saque a Cidade, vendo assim esta Capital a ter a mesma sorte que Cabo Verde". ${ }^{43}$ Por sua vez, Cabo Verde acabava de vivenciar um início de década (1830) muito conturbado em razão da forte seca, escassez de alimentos e morte de parte de sua população; além de lutas civis e o desamparo do governo central (RIBEIRO, 1997, p. 185).

Economicamente, a mais importante ilha do arquipélago apresentava 9:000\$000 réis de rendimentos públicos no ano de 1834. Santiago era composta por dois conselhos, 11 freguesias e 5.374 fogos. A população era de 19:932 livres e 1.714 escravos. A economia gravitava em torno da produção de milho, mandioca, café, açúcar, aguardente, frutos, gados, aves, azeite de purga e urzela. Parte dessa produção era exportada para a metrópole, Guiné, Estados Unidos e demais nações estrangeiras. ${ }^{44}$

$\mathrm{O}$ estado militar da província era "o mais miserável possível [...] e faz uma despesa inutil à Fazenda Pública com Officiaes e Soldados que para nada servem". ${ }^{45} \mathrm{O}$ aspecto militar é importante para, mais a frente, analisarmos a revolta escrava e a determinação do governador de fuzilar os "chefes". Ilustrando um pouco mais, apresentamos a força da tropa da ilha de Santiago, e citamos a descrição apresentada no Prospecto Economico-Estatistico de Cabo Verde do ano de 1834: "Pretos incapazes de dar um tiro sem fechar os olhos". ${ }^{46}$

Avançando um pouco no tempo, apresentamos o orçamento para Cabo Verde relativo ao ano financeiro de 1837-38. A receita estimada foi de 24:781\$744, enquanto a despesa atingiu 46:213\$263 réis. Fixando apenas no orçamento para a ilha de Santiago, o valor foi de 9:736\$620 e a despesa de 9:172\$000, mas sem considerar os gastos como a folha eclesiástica e a militar. $^{47}$

Em razão da escassez de alimentos, seca, baixo comércio, déficit financeiro e desejo emancipacionista por parte de sua elite; provavelmente, toda essa instabilidade, alicerçou a eclosão da revolta de 1835.

\section{Cabo Verde (1835): “a revolução de todos os escravos"}

No dia 6 de dezembro de 1835, na ilha de Santiago, ocorreu a "Revolução de todos os escravos [...] contra todos os proprietários e europeos", os quais "devião sem excessão alguma serem mortos". ${ }^{48}$ De acordo com o relato do juiz de direito, Jose Joaquim da Silva Guardado, o plano era "porem de noite fogo nas Palhoças que á num dos lados da Villa, e chamando alli a attenção do Povo e Tropa apoderarem-se dos Quarteis d'esta e do Paiol da pólvora e começarem então a carniceria". ${ }^{49}$

O objetivo de assassinar os proprietários e europeus nos recorda o ocorrido em Carrancas quando os escravos da família Junqueira "[...] estavam determinados a exterminar todos os brancos daquela propriedade" (ANDRADE, 2016)..$^{50}$ A semelhança do propósito de ambas as revoltas, Ilha de Santiago e Carrancas, pode nos levar ao anacronismo, mas o relacionamento objetiva-se propor questões (BARROS, 2007) ou, neste caso, salientar aspectos análogos quando da sublevação de escravizados. O ponto a destacar é o desejo de assassinar todos os brancos.

Porém, na ilha de Santiago o plano não se concretizou em razão de um escravo "convidado para entrar na Conspiração a delatou". ${ }^{51}$ Mesmo assim, houve o enfrentamento com a precária guarda da ilha. $\mathrm{Na}$ 
"Expozição" feita pelo governador geral da província, coronel Joaquim Pereira Marinho, encontramos:

aquelle dia às onse horas da noite no termo determinado pelos chefes revolucionários para incendiar esta Capital, e degolar seus habitantes, nossos paquettes avançados forão atacados em força por infantes, e cavalheiros; se algumas balas de calibre desoito não fulmissiassem por entre os rebeldes, talvez nossos pequenos paquetes succumbissem, e seria preciso empenhar em hum combate noturno toda a guarnição: então o sangue correria e sendo huma parte da guarnição Guardas Nacionaes alguns chefes de Família perecerião na luta ${ }^{52}$

A partir do conhecimento da insurreição e posterior enfrentamento, todos os "habitantes" da ilha de Santiago ficaram em "alarme, as tropas e cidadãos em armas". Como, num primeiro momento, não houve punição, a impunidade "dos chefes" poderia levar a outras conspirações. O próprio governador geral da província informou que o "terror está espalhado em todos os proprietarios; os chefes de família não se julgão com segurança; a todos os momentos esperão ver seus escravos sublevados apunhalarem suas esposas, seus filhos e destruírem seus bens." ${ }^{53}$

Por que assassinar? Seria a maneira encontrada para punir os responsáveis diretos pela violência sofrida no dia a dia? Ou apenas era vingança pelos maus tratos? Provavelmente, a intenção de assassinar esposas e filhos revelava algo mais do que vingança.

Diante da ameaça esperava pronta e rápida punição. Foi o que ocorreu. A fim de utilizar o castigo de alguns poucos escravos como exemplo, o governador geral fez "appresental-los aos does juises legaes" que "[...] perante elles os mesmos chefes declararão seus projetos de fogo, sangue e mortes, explicarão seu plano de revolução mostrando assim que esperavão com valor a morte, ou qualquer castigo". ${ }^{54}$ Ainda, segundo o governador, em razão da necessidade de apresentar aos escravos um "prompto exemplo" e por achar que as "formalidades do nosso processo produsir males e horrores irremediaveis fiz convocar em assemblea todos os proprietários, fasendo a presidir pelos interinos Juises de Direito e Delegado do Procurador Regio". ${ }^{55}$

Durante a assembleia foi apresentada a "unanimidade" das confissões dos "declarados" chefes subversivos e em razão do "perigo imminente em que estavão todos os proprietários, europeos [...]" declarouse a necessidade de apresentar um exemplo "porque toda a Ilha estava em perigo que os principaes cabeças devião ser logo afusilados, e os immediatos castigados rigorosamente". ${ }^{56}$

O receio das autoridades demonstra um dos pontos frágeis da sociedade escravocrata e do império que tinha no comércio de escravizados uma das principais arrecadação, sendo o recolhimento alfandegário sua principal fonte de receita (SOUZA, 2020).

$\mathrm{Na}$ urgência do retorno da normalidade e do receio das "formalidades do nosso processo produzir males e horrores irremediáveis [...]" ${ }^{17}$, as autoridades optaram por penalizar os responsáveis sem a devida apuração pela Justiça solicitada pelo Delegado do Procurador Régio, João José Antonio Frederico. De acordo com a Exposição do ocorrido encaminhada pelo governador ${ }^{58}$, o mencionado Delegado "se apresentou como campeão valente da defesa das formalidades [...]" - Mas, de acordo com o próprio governador a opção pela execução dos líderes ocorreu após a convocação de um conselho que reuniu todos os proprietários de escravizados da ilha de Santiago, no qual foi decidido, por unanimidade, o fuzilamento dos chefes "porque se não houvesse hum tal exemplo nenhum homem livre nem proprietário podia contar com a vida". ${ }^{60}$ Após a assembleia, o governador para "convencer legalmente de seus crimes foi apresenta-los [chefes da revolta] a does Juízes Legaes [...] perante eles os mesmos chefes declararão seus projetos de fogo, sangue e mortes $[\ldots] "{ }^{61}$

A justificativa apresentada para a não apuração do ocorrido pela Justiça deu-se em razão do "numero de escravos he mui superrior as forças com que os podemos rebater em tal circunstância o único meio de restabelecer a segurança e o sucego publico he fazer punir esta rebelião afusilando os chefes principaes e castigando asperamente os immediatos aos mesmos chefes" ${ }^{62}$ Seria o número de escravizados tão superior? E a força e o estado da Guarnição existente?

No Prospecto Estatístico-Econômico da Província do ano de 1834, elaborado pelo deputado por Cabo Verde José Joaquim Lopes de Lima há o relato do estado do Corpo Militar do arquipélago ser "o mais miserável possível, tanto material, como no pessoal." ${ }^{63} \mathrm{O}$ documento informa também os dados sobre a população da ilha de Santiago, ${ }^{64}$ local em que deflagrou a revolta escrava.

Tabela 2. População de Santiago $(1834)^{63}$.

\begin{tabular}{|l|l|l|}
\hline & Livres & Escravos \\
\hline Santiago & 19.932 & $\mathbf{1 . 7 1 4}$ \\
\hline
\end{tabular}

Fonte: Elaborada pelo autor.

Se a população escrava não era assim tão expressiva, o contingente da tropa era praticamente inexistente. O próprio governador, coronel Joaquim Pereira Marinho, destacou que a "guarnição he pouca [...] há so nove Officiaes promptos estando eu neste numero, alguns destes já parecem sentirem-se ameaçados das febres do país: os officiaes inferiores estão no mesmo estado $[\ldots]$ ".. ${ }^{66}$

A explicação do governador demonstra que o maior receio é a percepção dos revoltosos da incapacidade de controle da revolução por parte do 
governo da província, por conseguinte, da força militar; pois a fragilidade da força, indicada na documentação, era do conhecimento dos proprietários e, provavelmente, dos escravizados.

Há mais questões para além da precária e frágil força policial. Como citado anteriormente, a Guarnição não recebia os soldos devidos o que ocasionou a sublevação na Praça de São Joze de Bissau em 1826 e a própria "officialidade e Empregados públicos" encontravam-se sem o recebimento de seus benefícios. Outro ponto era a composição das tropas que veremos à frente.

Vejamos: em ofício encaminhado juntamente com o documento "Expozição" é relatado pelo governador que após lavrar em assembleia a "acta de morte aos reos" foi tomada outra decisão de "entregar a Justiça os escravos," o que levou o coronel Joaquim Pereira Martinho a "pôr-me em armas até eu e minha pouca e má guarnição acabar-mos nas posições". ${ }^{68}$

O medo demonstrado nas próprias palavras do governador Joaquim Pereira Martinho era resultado da decisão contrária à execução dos "chefes" da revolução que ocasionou a visita dos proprietários "em corporação ao meu quartel pedindo que lhe fisesse Justiça". ${ }^{69}$

Ao que parece, a visita dos proprietários foi mais uma ameaça frente à decisão da comissão de "morte aos réus". Um segundo ponto, que acreditamos ter contribuído para a decisão de executar os "chefes," foi a incapacidade da concretização de "hum Conselho Militar para me pôr em respeito para com toda a Ilha, porque não tinha Officiaes para elle; só tinha promptos alguns Alferes rapazes e poucos instruídos". ${ }^{70}$ E o motivo para a não concretude era "de maneira alguma confiar na pouca Tropa que tinha por ser toda de pretos, recrutas buçaes que ainda não tinha tido tempo para queimar huma escova e temendo que os soldados tomassem o partido dos escravos por serem todos da mesma cor, e oriundos das mesmas Naçoens". ${ }^{71}$

Mesmo após lavrar a ata "de morte" dos réus e da nomeação da comissão, "[...] por meio de escrutenio secreto, para rever o processo e escolher entre os reos mais criminosos aquelles que deverião servir ao exemplo $[\ldots] ", 72$ o procurador régio "condusio para sua casa o processo e, posteriormente remeteu-o ao quartel do governador "hum Officio em que me declarava invasor da Carta Constitucional, e dos poderes políticos, pedidome que entregasse os Chefes Revolucionarios ao poder judiciário". ${ }^{73}$

A situação do governador era delicada, dispunha de escassa força militar, tinha o procurador régio contrário a sua decisão que levou os proprietários a defenderam seus bens "visitando-o" em favor da não execução dos "chefes". Mesmo isolado Joaquim Pereira Marinho, crente na necessidade de evitar o "contagio revolucionário que se pode espalhar pelas outras Ilhas e possessoens [...], senão exterminando por huma vez os chefes da Revolução [...]" determinou que no dia quatorze de dezembro de 1835 às 11 horas "no Campo da Boa Vista fazer um castigo exemplar em todos os chefes revolucionários: assim os commandantes de todas as povoaçoens desta Illha farão presenciar aquelle castigo por hum escravo de cada povoação que seja mais capaz de explicar aos outros a punição que virão dar aos rebeldes". ${ }^{74}$

\section{Conclusão}

Trata-se de um período de deslocação de um império antes centrado no Brasil, no qual se buscava promover a agricultura em seus domínios em África por meio da diminuição da tarifa sobre a comercialização na metrópole dos gêneros oriundos das possessões. Contudo, por ter estruturado o império em torno das riquezas e do comércio realizado pela ex-colônia, a fragilidade e a dependência do abastecimento ficaram evidentes ocasionando, ainda na década de 1820, o desejo de união de Cabo Verde ao Brasil.

Além da necessidade do império português em se reinventar em sua nova configuração, o momento em que ocorreu a revolta na ilha de Santiago em Cabo Verde era politicamente delicado. O próprio governador no desejo de apresentar castigo exemplar aos líderes foi considerado "invasor da Carta Constitucional" pelo procurador régio.

A acusação isolou o governador que, aparentemente, contava apenas com tropas frágeis e insubordinadas compostas por negros "oriundos das mesmas nações" que os revoltosos e "incapazes de dar um tiro." A divergência pós fuga entre o governador e o procurador régio, não existia antes do ocorrido, não sendo possível observar a interferência de disputa entre as autoridades ou até mesmo entre os senhores locais que tenha influenciado na conflagração.

O desejo dos escravizados de assassinar os brancos e europeus, possivelmente, ocorreu, para além dos maus tratos, em razão do conhecimento da composição da força militar, de seu estado e, de modo geral, da própria dificuldade da administração da ilha de Santiago e do arquipélago em obter da metrópole solução para o desenvolvimento agrícola e da incapacidade econômica para o cumprimento de obrigações como o pagamento dos funcionários.

A inépcia refletia na força militar da província, que além de escassa não tinha a capacidade de resistir a assalto de maior proporção. O fuzilamento dos líderes indica que o terror do governador em sucumbir a incursão era a representação, não do desejo de liquidar os revoltosos "mais criminosos", mas sim, dos "chefes de famílias" temendo a morte de "suas esposas, seus filhos, e destruírem seus bens." 75 


\section{Notas}

1. Familiares de alguns dos membros da tripulação que acompanharam António Noli, capitão-donatário do sul da Ilha de Santiago. De acordo com António Carreira, a ilha de Santiago foi dividida em duas capitanias: a do sul entregue a António Noli, como prémio pela descoberta; a segunda ao norte entregue a Diogo Afonso, contador da ilha da Madeira. Este ao contrário de António Noli, não residiu na ilha.

2. Antigo mapa de Cabo Verde, publicado em 1902, na Encyclopædia Britannica. Disponível em: http://www.africa-turismo.com/cabo-verde/ mapas.htm. Acesso: 08 jun. 2019.

3. Para ser alforriado, o escravo deveria apresentar, obrigatoriamente, o passaporte emitido nas colônias pelas autoridades. Sem tal documento o africano escravizado não obtinha a alforria. Já o Alvará régio de 1773 aboliu o princípio de hereditariedade, ambos sem questionarem a escravidão extinta em Portugal somente em 1869.

\section{PT/AHU/CU. Cabo Verde. Cx 64, doc. 6}

5. Boato significava "a notícia ou a novidade que se dá claramente em altas vozes”. In: SILVA, Antonio Moraes. Diccionario da língua portugueza. Lisboa: Typographia Lacerdina, 1813, p. 285. Ou, de acordo com Raphael Bluteau, "estrondo da fama ou de uma nova opinião ou de coisa que se espera com grande alvoroço" Bluteau, Raphael. Vocabulario portuguez\& latino. Coimbra: Collegio das Artes da Companhia de Jesus, 1728, p. 133.

6. António Pusich foi governado de Cabo Verde entre 1818-1822.

7. D. João VI faleceu em 10 de Março de 1826.

8. Ofício do governador ao ministro e secretário de Estado dos Negócios Ultramarinos e da Marinha, Joaquim José Monteiro Torres. PT/AHU/CU Cabo Verde, Cx 84, doc. 27.

9. Art. $1^{\circ}$ "que por espaço de dez anos [...] todos, e quaisquer generos, que se importarem, ou que se exportarem dos Portos do Reino de Angola e Benguela em directura para os destes Reino de Portugal serão isentos da metade dos direitos [...]". Alvará de 6 de dezembro de 1824. Disponível em: http://legislacaoregia.parlamento.pt/V/1/12/61/p2. Acesso: 09 fev. 2017.

10. "[...] historians interested in results, in concrete policy, are prone, perhaps justifiably, to ignore the many unrealized projects that proliferated $[\ldots]$ ”.

11. José António Ferreira Braklami (1780-1847) eleito primeiro substituto pela divisão do Algarve, mas não chegou a ser chamado. Só tomou assento nas Cortes na legislatura cartista de 1826-1828 eleito pela província do Algarve.

12. Debates Parlamentares da Câmara dos Senhores deputados da Nação Portuguesa 1822-1910. Lisboa, 11 de dezembro de 1826. Disponível em http://debates.parlamento.pt/catalogo/mc/cd/01/01/01/030/1826-12-11?sft= true $\& \mathrm{q}=\mathrm{caf} \% 25 \mathrm{C} 3 \% 25 \mathrm{~A} 9 \& \mathrm{pOffset}=480 \& \mathrm{pPeriodo}=$ mc $\&$ Publicacao $=\mathrm{cd} \#$ p153. Acesso: 10 maio 2017.

13. PT/AHU/CU - Cabo Verde, cx 85A, doc 81.

14. PT/AHU/CU - Cabo Verde, cx 85A, doc 81.

15. PT/AHU/CU - Cabo Verde, Cx 85, doc 35. O café foi carregado junto com peles e couro. Uma única vez, junto com panos.

16. Das embarcações que mais geraram receita, três eram norte-americanas e apenas uma portuguesa.

17. Existiu outra embarcação estrangeira, mas não foi possível decifrar sua origem.

18. O reconhecimento da independência do Brasil por Portugal ocorreu em 1825 .

19. Guiné foi administrada como colónia das ilhas de Cabo Verde até 1879.

20. PT /AHU/CU - Cabo Verde, Cx 83, doc 44.

21. O ataque ocorreu nos dias 13, 14 e 15 de dezembro de 1825. PT /AHU/ CU - Cabo Verde, Cx 83, doc 44.

22. PT /AHU/CU - Cabo Verde, Cx 85, doc 61.

23. PT /AHU/CU - Cabo Verde, Cx 84, doc 72.
24. Movimento republicano e separatista ocorrido em 2 de julho de 1824 em Pernambuco que se expandiu no Nordeste do Brasil.

25. Ocorrida entre 1825 a 1828 com a derrota do exército imperial. Em 1829 ocorreu a crise financeira que culminou com o fechamento do Banco do Brasil.

26. O comércio de escravizados passou a ser considerado pirataria a partir de 13 de março de 1830 .

27. D. Pedro I no Brasil e d. Pedro IV em Portugal.

28. O Brasil perdeu a guerra em 1827 e, por conseguinte, o território da Província da Cisplatina, garantindo o surgimento do Uruguai. No ano seguinte foi assinado o tratado de paz com intermediação inglesa.

29. A insurreição de Carrancas aconteceu em 13 de maio de 1833.

30. No período regencial do Brasil, revoltas aconteceram de norte a sul: Citamos: Cabanagem - Pará - (1835 - 1840); Sabinada - Bahia - (1837 1838); Balaiada - Maranhão - (1838 - 1840) e Revolução Farroupilha ou Guerra dos Farrapos (1835 - 1845)

31. Ver também do mesmo autor: O ergue-se [?] do império português após o reconhecimento da independência do Brasil(1825-1835). In: Revista Mosaico. V.11 n.2 (2020). Disponível em: http://editora.universidadedevassouras.edu. br/index.php/RM/article/view/2479. Acesso em 2 fev. 2020.

32. Alvará régio de 14 de dezembro de 1829. Disponível em: http:// legislacaoregia.parlamento.pt. Acesso: 6 ago. 2017.

33. Capitão da embarcação norte-americana Fredonia que partiu da ilha de Santiago.

34. Ofício do Encarregado de Negócios de Sua Majestade nos Estados Unidos da América. PT/AHU/CU - Cabo Verde. Cx, 97 doc 101.

35. PT/AHU/CU - Cabo Verde. Cx, 97 doc 101.

36. PT/AHU/CU - Cabo Verde. Cx, 97 doc 101.

37. PT/AHU/CU - Cabo Verde. Cx 98, doc 23.

38. PT/AHU/CU - Cabo Verde. Cx , 53, doc(?).

39. PT/AHU/CU - Cabo Verde. Cx 98, doc 7.

40. PT/AHU/CU - Cabo Verde. Cx, 97, dos 25.

41. Debates Parlamentares das Cortes Gerais da Nação Portuguesa 1828 Lisboa, 8 de março de 1828. Disponível em: http://debates.parlamento.pt

42. PT/AHP/ Secção I/II, Cx, 430, Maço 315, doc, 86.

43. Para além da revolta escrava de Cabo Verde, Moçambique em 1836 vivenciou a Rebelião do Corpo artilharia da Praça de São Sebastião e o Conflito entre o Governador e a Junta governativa. PT/AHU/SEMU- DGU - Moçambique, Cx 3, doc 3 e 5.

44. PT/AHU/SEMU- DGU - Cabo Verde, Cx 53, doc [?].

45. Idem.

46. Idem.

47. PT/AHU/SEMU- DGU - Cabo Verde, Cx 55, doc [?].

48. PT/AHU/SEMU- DGU - Cabo Verde, Cx 54, doc [?].

49. PT/AHU/SEMU- DGU - Cabo Verde, Cx 54, doc [?].

50. A propriedade mencionada era a Bela Cruz, mas a revolta também ocorreu na propriedade de Campo Alegre.

51. PT/AHU/SEMU- DGU - Cabo Verde, Cx 54, doc [?].

52. PT/AHU/SEMU- DGU - Cabo Verde, Cx 54, doc [?].

53. PT/AHU/SEMU- DGU - Cabo Verde, Cx 54, doc [?]. Grifo Nosso.

54. PT/AHU/SEMU- DGU - Cabo Verde, Cx 54, doc [?]. 
55. PT/AHU/SEMU- DGU - Cabo Verde, Cx 54, doc [?].

56. PT/AHU/SEMU- DGU - Cabo Verde, Cx 54, doc [?]. Grifo nosso.

57. PT/AHU/SEMU- DGU - Cabo Verde, Cx 54, doc [?].

58. Após a análise da comunicação sobre a revolta, pareceu-nos que o governador não tinha ou não fez uso da prerrogativa sobre a vida do escravizado. Insta salientar, que o regimento dos governadores foi extinto, no caso do Brasil, em 1808 após o estabelecimento da Corte na colônia.

59. PT/AHU/SEMU- DGU - Cabo Verde, Cx 54, doc [?].

60. Idem.

61. Idem.

62. Idem.

63. PT/AHU/SEMU- DGU - Cabo Verde, Cx 53, doc [?].

64. A ilha de Santiago produzia: milho, mandioca, café, açúcar, aguardente, "grande cópia de frutos", criação de gados e aves, "muito azeite de purga e urzela". PT/AHU/SEMU- DGU - Cabo Verde, Cx 53, doc [?]. A Ilha de Santiago é conhecida historicamente pelo seu papel que teve no comércio de escravizados. Recentemente, em outra pesquisa em andamento, descobrimos a existência de cafeeiros na Ilha de Santiago no ano de 1754 que refuta a informação da "chegada" do café em 1790 na ilha de São Nicolau. A memória assim informa: Lori-cluejerel achai a S. Iago , l'unedesIflesdu Cap-verd, le premier Mars 1754, j'y vis des Cafeiers plantes a l'abri de grandsarbres\& ar-Tofesdurantlesfechereffes par desrigolespratiqueespourcetufage: cesarbres, eleves d'environfeptpieds , eroient d'une belle verdure\& charges de fruits, leursbranches\&rameauxs 'etendoienten tout fens.Jean-Baptiste-Christophe-FuséeAublet. Histoire des plantes de laGuianefrançoise: rangéessuivantlaméthodesexuelle ;avecplusieursmémoiressurdifférensobjetsintéressans, relatifs à laculture\&aucommerce de laGuianefrançoise, \& une noticedes plantes de l'Isle-de-France.Paris, 1775.

Disponível em: https://books.google.pt/books?id=XIBxf-ZfrEUC\&printsec $=$ frontcover $\& \mathrm{dq}=\mathrm{J}$ ean + Fus $\% \mathrm{C} 3 \% \mathrm{~A} 9 \mathrm{e}+$ Aublet $\& \mathrm{hl}=\mathrm{pt}-\mathrm{PT} \& \mathrm{sa}=\mathrm{X} \& \mathrm{ved}=0 \mathrm{ah}$ UKEwjZqK6cpovbAhXKOxQKHQifCI8Q6AEIKjAA\#v=onepage\&q=Jea n\%20Fus\%C3\%A9e\%20Aublet\&f=false. Acesso: 6 ago. 2018. Informação cedida gentilmente pela professora Eugénia Rodrigues.

65. PT/AHU/SEMU- DGU - Cabo Verde, Cx 53, doc [?].

66. PT/AHU/SEMU- DGU - Cabo Verde, Cx 54, doc [?].

67. Optamos por esta denominação em razão da documentação e do próprio governador se referir a Cabo Verde como província. Contudo, temos conhecimento que o Estado Novo passou a designar as colónias por províncias ultramarinas, considerando que esses territórios não eram colónias, mas sim parte integrante e inseparável de Portugal.

68. PT/AHU/SEMU- DGU - Cabo Verde, Cx 54, doc [?].

69. PT/AHU/SEMU- DGU - Cabo Verde, Cx 54, doc [?].

70. PT/AHU/SEMU- DGU - Cabo Verde, Cx 54, doc [?].

71. PT/AHU/SEMU- DGU - Cabo Verde, Cx 54, doc [?]. Grifo nosso.

72. PT/AHU/SEMU- DGU - Cabo Verde, Cx 54, doc [?].

73. PT/AHU/SEMU- DGU - Cabo Verde, Cx 54, doc [?].

74. Idem.

75. PT/AHU/SEMU- DGU - Cabo Verde, Cx 54, doc [?].

\section{Abreviaturas}

AHU- Arquivo Histórico Ultramarino.

AHP - Arquivo Histórico Parlamentar.

BNL- Biblioteca Nacional de Lisboa.

CU- Conselho Ultramarino.
DGU - Direcção Geral do Ultramar.

PT- Portugal.

Ultramar.

SEMU- Secretaria de Estado da Marinha do

\section{Fontes Primárias}

\section{Arquivo Histórico Ultramarino}

Conselho Ultramarino.

Avulsos:

Cabo Verde:

PT/AHU/CU. Cabo Verde. Cx 64, doc. 6.

PT/AHU/CU - Cabo Verde, cx 85A, doc 81.

PT/AHU/CU - Cabo Verde. Cx , 53, doc

[?]. Esta descrição com interrogação entre parênteses, refere-se a documentos que ainda não foram numerados PT/AHU/CU - Cabo Verde. Cx, 97, dos 25.

PT/AHU/CU - Cabo Verde. Cx 98, doc 7.

PT /AHU/CU - Cabo Verde, Cx 83, doc 44.

PT /AHU/CU - Cabo Verde, Cx 85, doc 61.

PT/AHU/CU - Cabo Verde, Cx 84, doc 27.

PT /AHU/CU - Cabo Verde, Cx 84, doc 72.

PT/AHU/CU - Cabo Verde. Cx, 97 doc 101.

PT/AHU/CU - Cabo Verde. Cx 98, doc 23.

\section{Secretaria de Estado da Marinha e Ultramar}

Avulsos:

\section{Cabo Verde:}

PT/AHU/SEMU- DGU - Cabo Verde, Cx 53, doc [?].

PT/AHU/SEMU- DGU - Cabo Verde, Cx 54, doc [?].

PT/AHU/SEMU- DGU - Cabo Verde, Cx 55, doc [?].

\section{Moçambique:}

PT/AHU/SEMU- DGU - Moçambique, Cx 3, doc 3. $\operatorname{doc} 5$

PT/AHU/SEMU- DGU - Moçambique, Cx 3,

Parlamento Português:

PPT/AHP/ Secção I/II, Cx, 430, Maço 315, doc, 86.

\section{Documentação disponivel online}

Legislação Régia - Disponível em: http:// 
legislacaoregia.parlamento.pt

Alvará de 6 de dezembro de 1824.

Alvará régio de 14 de dezembro de 1829.

Debates Parlamentares - Disponível em: http:// debates.parlamento.pt

Debates Parlamentares da Câmara dos Senhores deputados da Nação Portuguesa 1822-1910. Lisboa, 11 de dezembro de 1826.

Debates Parlamentares das Cortes Gerais da Nação Portuguesa 1828. Lisboa, 8 de março de 1828.

\section{Fonte Impressa:}

Jean-Baptiste-Christophe-FuséeAublet. Histoire des plantes de la Guiane françoise: rangées suivant la méthode sexuelle; avec plusieurs mémoires sur différens objets intéressans, relatifs à laculture \& au commerce de la Guiane françoise, \& une notice des plantes de l'Isle-de-France. Paris, 1775.

\section{Referências}

ALEXANDRE, Valentim. A questão colonial no Parlamento (1821-1910). v. I. Lisboa: Dom Quixote, 2008.

ANDRADE, Marcos Ferreira de. Rebeldia escrava na comarca do Rio das Mortes, Minas Gerais: o caso Carrancas. Afro-Ásia. Salvador, n. 21-22:4582, 1998-1999.

ANDRADE, Marcos Ferreira de. A pena de morte e a revolta dos escravos de Carrancas: a origem da"lei nefanda" (10 de junho de 1835). Tempo [online]. 2017, v. . 23, n. 2, p.264-289.

BALENO, Ilídio. A afirmação da sociedade cabo-verdiana a partir da crise dos séculos XVII e XVIII. In: LANG, Jürgen. Cabo Verde - origens da sua sociedade e do seu crioulo. 2006

BARROS, José D.'Assunção. História comparada: um novo modo de ver e fazer a história. Revista de História comparada, v. 1, n. 1, p. 1, 2007. Disponível em: https://www.researchgate.net/publication/320014010. Acesso: 2 fev. 2021

BLUTEAU, Raphael. Vocabulario portuguez \& latino. Coimbra: Collegio das Artes da Companhia de Jesus, 1728.

CAPELA, José. Escravatura: a empresa de saque, o abolicionismo. Porto: Afrontamento, 1974.

CARREIRA, António. Cabo Verde: formação e extinção de uma sociedade escravocrata (1460 - 1878). 2. Ed. Mem Martins: Gráfica EuropamLda, 1983.

CASTRO, Zília Osório de (Direcção). Dicionário do Vintismo e do primeiro Cartismo (1821-1823 e 1826-1828). Vol. I. Lisboa: Edições Afrontamento, 2002.

ENGEMANN, Carlos. De laços e de nós. Rio de Janeiro; Apicuri, 2008.

PAQUETTE, Gabriel. After Brazil. In: Journal of Colonialism and Colonial History, v. 11, n.2, 2010.

PEREIRA, Daniel A. Novos subsídios para a história de Cabo Verde (século XIX). Rosa de Porcelana, Lisboa, 2016.

PEREIRA, Eduardo Adilson Camilo. Cabo Verde: Elites Coloniais e Lutas Partidárias na Primeira Metade do Séc. XIX (1821-1841). Sankofa (São Paulo), São Paulo, v. 6, n. 10, p. 129-149, jan. 2013. Disponível em: https:// www.revistas.usp.br/sankofa/article/view/88897. Acesso: 1 ago. 2016.

REIS, João José. Rebelião escrava no Brasil: a história do levante dos malês em 1835. 3. ed. São Paulo: Companhia das Letras, 2012.
RIBEIRO, Orlando. A Ilha do Fogo e as suas erupções. Lisboa: Comissão Nacional para as comemorações dos Descobrimentos Portugueses, 1997.

SANTOS, Danilo de Jesus da Veiga. O Cabo-verdiano através dos olhos de forasteiros: representações nos textos portugueses (1784-1844). Dissertação de Mestrado. Departamento de História da Faculdade de Letras da Universidade de Lisboa, 2011. Disponível em: https://repositorio.ul.pt/ handle/10451/4152. Acesso: 9 dez. 2018.

SILVA, Antonio Moraes. Diccionario da língua portugueza. Lisboa: Typographia Lacerdina, 1813.

SILVA, Eduardo e Reis, João. Negociação e Conflito: a resistência negra no Brasil escravista. São Paulo: Companhia das Letras, 1989.

SOUZA, Alan de Carvalho. Terras e Escravos: a desordem senhorial no Vale do Paraíba. Jundiaí, Paco Editorial: 2012.

SOUZA, Alan de Carvalho. Do Brasil para África: o café na viragem do império português (1807-1850). Tese. Programa Interuniversitário de Doutoramento em História - Universidade de Lisboa, ISCTE - Instituto Universitário de Lisboa, Universidade Católica Portuguesa e Universidade de Évora. Lisboa, 2020.

SOUZA, Alan de Carvalho. O ergue-se [?] do império português após o reconhecimento da independência do Brasil (1825-1835). Revista Mosaico. v. 11 n. 2, 2020. Disponível em: http://editora.universidadedevassouras.edu. br/index.php/RM/article/view/2479. Acesso: 2 fev. 2021. 